\title{
A 75-Year-Old Female with Left Anterior Descending Coronary Artery Originating from the Right Coronary Artery Presenting with Recurrent Major Bleeding due to Dual Antiplatelet Therapy Managed with Percutaneous Coronary Intervention and Ticagrelor Monotherapy
}

\author{
Bekele Alemayehu Shashu, MD*
}

Internist, Interventional Cardiologist, School of Medicine, Addis Ababa University, Ethiopia

*Corresponding author: Bekele Alemayehu Shashu, MD, Internist, Interventional Cardiologist, School of Medicine, Addis Ababa University, Ethiopia

\begin{abstract}
A 75-year-old female with unstable angina who was found to have anomalous left anterior descending coronary artery originating from the right coronary artery close to the ostium presented with recurrent major bleeding while on dual antiplatelet therapy with aspirin and clopidogrel following percutaneous coronary intervention despite treatment with proton pump inhibitor and blood transfusion. When aspirin was discontinued the bleeding episodes subsided for 5 months which was followed by return of the patient with non ST segment elevation myocardial infarction with tight stenosis of the same artery proximal to the previous stent. A successful repeat percutaneous coronary intervention was performed with ticagrelor monotherapy without any bleeding or ischemic episodes for more than one year.
\end{abstract}

\section{Abbreviations}

MI: Myocardial Infarction; LAD: Left Anterior Descending; RCA: Right Coronary Artery; ACS: Acute Coronary Syndrome; PCl: Percutaneous Coronary Intervention; TIMI: Thrombolysis in Myocardial Infarction; UGI: Upper Gastrointestinal; CABG: Coronary Artery Bypass Grafting; DAPT: Dual Antiplatelet Therapy

\section{Introduction}

Coronary artery anomalies have been discovered as incidental findings during angiography, surgery and autopsy as component of complex congenital malformations of the heart or may be an isolated defect [1]. Anomalous origin and course of the coronary arteries may remain asymptomatic, or may cause chest pain, sudden death, cardiomyopathy, syncope, dyspnea, ventricular fibrillation and MI [2]. The determination of variations in the course and origin of the major coronary arteries is important in coronary surgery and angiography. Evidences derived from angiographies performed for suspected obstructive disease determined that coronary anomalies affect about $1 \%$ of the general population [3]. Abnormal origin of left anterior descending (LAD) coronary artery from the right coronary artery (RCA) is a rare anomaly in coronary angiogramswhile its occurrence is in $4 \%$ of the patients with tetralogy of Fallot $[4,5]$.

Among patients who have an acute coronary syndrome (ACS) or who have undergone percutaneous coronary intervention $(\mathrm{PCl})$, the risk of thrombotic events is lower with dual antiplatelet therapy (DAPT) with aspirin and a $\mathrm{P} 2 \mathrm{Y} 12$ receptor inhibitor than with aspirin alone [6]. Post-PCl bleeding has been shown to be associated with a substantial and durable risk of death, approximating or even exceeding that associated with MI [7]. Avoidance of aspirin therapy may allow for more prolonged use of potent P2Y12 inhibitors curtailing aspirin-related bleeding risk, particularly with respect to gastrointestinal toxicity.

Citation: Shashu BA (2021) A 75-Year-Old Female with Left Anterior Descending Coronary Artery Originating from the Right Coronary Artery Presenting with Recurrent Major Bleeding due to Dual Antiplatelet Therapy Managed with Percutaneous Coronary Intervention and Ticagrelor Monotherapy. Int J Clin Cardiol 8:244. doi.org/10.23937/2378-2951/1410244 


\section{A}

B

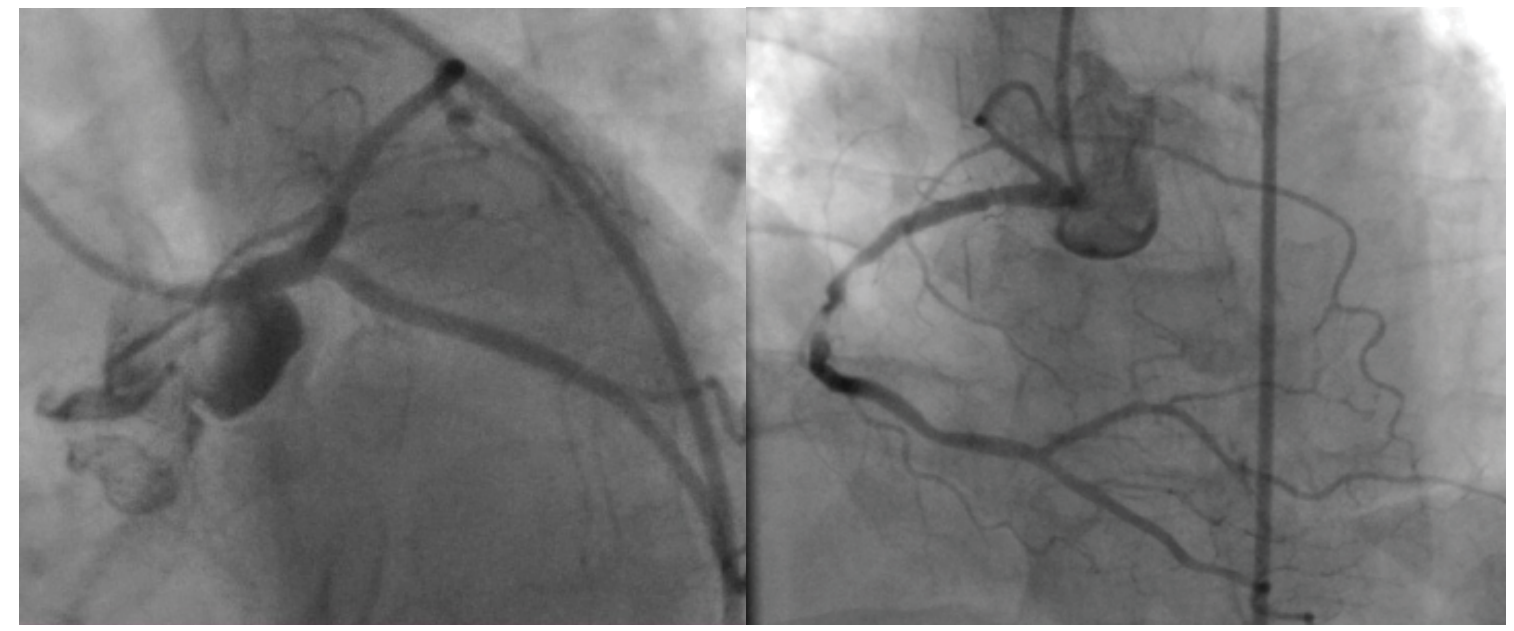

Figure 1: A) left coronary artery without LAD territory; B) Dominant RCA with long segment tight stenosis and LAD originating from proximal RCA.

\section{Case Report}

Presence of LAD coronary artery emerging from RCA is classified among the rare coronary anomalies and successful $\mathrm{PCl}$ with long lasting result using a single antiplatelet agent is exceptional. I herein report a 75-year-old diabetic and hypertensive female who presented to Gesund Cardiac and Medical Center, Addis Ababa, Ethiopia, before one year with typical angina triggered by minor activities of one month duration whose coronary angiography showed normal circumflex coronary artery, anomalous LAD originating from the RCA adjacent to the ostium and long segment 95\% stenosis of mid RCA (Figure 1) with recurrent major bleeding on DAPT who was successfully managed with ticagrelor monotherapy following $\mathrm{PCl}$.

During her initial presentation, cautious $\mathrm{PCl}$ was done using resolute integrity stent (zotarolimus eluting) resulting in thrombolysis in myocardial infarction (TIMI) III flow and she was continued with aspirin $81 \mathrm{mg} /$ day, clopidogrel $75 \mathrm{mg} /$ day, atorvastatin $40 \mathrm{mg} /$ day, metoprolol succinate $25 \mathrm{mg} /$ day and pantoprazole 40 $\mathrm{mg} /$ day. After two weeks, she came back with profound fatigue, dyspnea, pallor, tarry stool, and hemoglobin of $8 \mathrm{~g} \%$. Upper gastrointestinal (UGI) endoscopy, done after stabilization of the patient with 2 units of whole blood, revealed erosive gastritis which was managed with intravenous proton pump inhibitor.

Despite this, the patient had to present for 3 other episodes of UGI bleeding over 4 months and she was managed similarly. After the $4^{\text {th }}$ episode of bleeding, aspirin was desperately discontinued while the remaining medications were maintained. This was followed by 5 months of clinical stability without bleeding, fatigue or chest pain. Nine months after the initial presentation, she developed chest pain at rest with T-wave inversions involving the inferior leads plus elevated troponin congruent with acute MI. A repeat

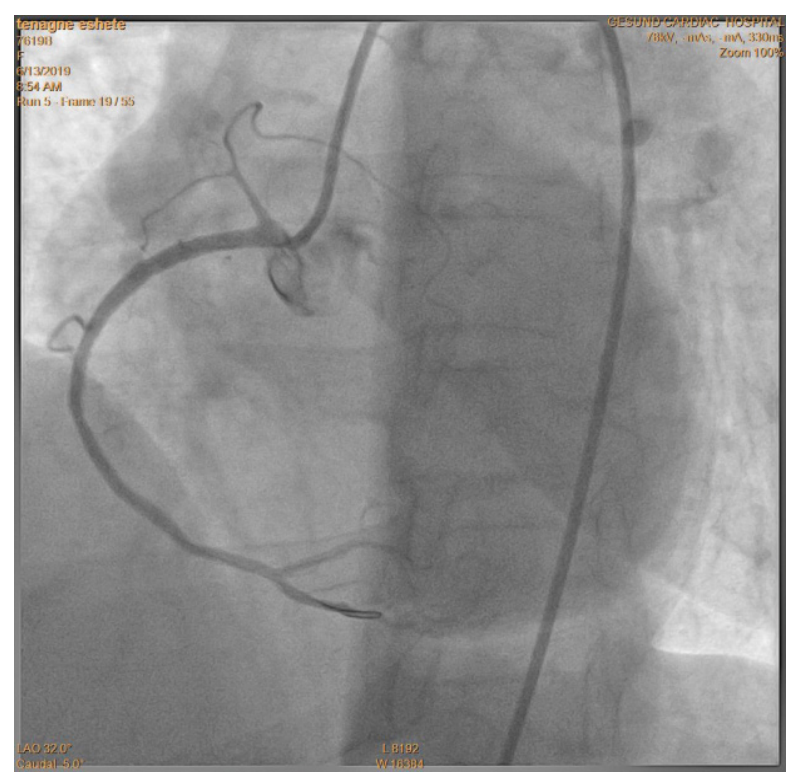

Figure 2: Final result after the repeat $\mathrm{PCl}$ on the proximal RCA.

coronary angiography showed a new discrete 90\% stenosis of the proximal RCA distal to the origin of the anomalous LAD with fully patent previously stented segment. This time again, $\mathrm{PCl}$ was done with successful result using the same type of stent while ticagrelor was utilized as the sole antiplatelet agent (Figure 2). She is comfortable up until now without chest pain or any bleeding episode for over one year.

\section{Discussion}

Abnormal origin of LAD coronary artery from the RCA is a very rare anomaly in coronary angiograms [4]. In this patient, the origin of LAD was very close to the RCA ostium which required immense care in the course of $\mathrm{PCl}$ to circumvent complications. During the second episode of ACS with intense chest pain and troponin positivity, to avoid the GI toxicity of aspirin, coronary 
artery bypass grafting ( $C A B G$ ) was considered, but she was deemed high surgical risk because of the debilitating effect of the recurrent bleeding. Performance of $\mathrm{PCl}$ with a single antiplatelet agent, ticagrelor, has proven successful in this elderly patient at high risk for bleeding as well as thrombotic complications.

Among patients who have undergone $\mathrm{PCl}$, the risk of thrombotic events is lower with dual antiplatelet therapy with aspirin and a $\mathrm{P} 2 \mathrm{Y} 12$ receptor inhibitor than with aspirin alone [6]. In the Ticagrelor vs. Clopidogrel in Patients with Acute Coronary Syndromes (PLATO) trial, ticagrelor, a reversible and direct-acting oral antagonist of the adenosine diphosphate (ADP) receptor P2Y12, which provides faster, greater, and more consistent P2Y12 inhibition than clopidogrel, was shown to reduce the rate of death from vascular causes, MI, or stroke without an increase in the rate of overall major bleeding when added to aspirin replacing clopidogrel [8]. Despite these remarkable achievements, post- $\mathrm{PCl}$ bleeding due to DAPT has been associated with a substantial risk of death, approximating or even exceeding that associated with MI [9].

Reducing the duration of aspirin therapy may allow for more prolonged use of potent P2Y12 inhibitors while avoiding aspirin-related bleeding risk, particularly with respect to $\mathrm{Gl}$ toxicity. In the Ticagrelor with or without Aspirin in High-Risk Patients after PCI (TWILIGHT) trial ticagrelor monotherapy was superior to ticagrelor plus aspirin to lower the incidence of clinically relevant bleeding with no higher risk of death, $\mathrm{MI}$, or stroke when started after 3 months of DAPT following PCI [10]. In my steadfast observation, it was apparent that my patient would not tolerate dual antiplatelet therapy for 3 months. Given the broad study population in the PLATO trial and the aforementioned study showing the benefit of ticagrelor monotherapy, I desperately decided to do a repeat $\mathrm{PCl}$ with ticagrelor alone from day one, after proper counselling of the patient and her family, with gratifying result without bleeding or thrombotic events for over one year. A recent study has also reported similar results to that of TWILIGHT trial instituting ticagrelor monotherapy 3 months after $\mathrm{PCl}$ done in ACS patients [11].

\section{Conclusion}

Successful $\mathrm{PCl}$ was done in the presence of a rare coronary anomaly, LAD originating from the RCA close to the RCA ostium, requiring immense care in the course of the procedure to avoid complications. Performance of $\mathrm{PCl}$ in a high risk patient with ticagrelor monotherapy from day one has been successful to avoid DAPT, particularly aspirin related recurrent bleeding and thrombotic complications.

\section{References}

1. Gowda RM, Chamakura SR, Doğan OM, Sacchi TJ, Khan IA (2003) Origin of left main and right coronary arteries from right aortic sinus of Valsalva. Int J Cardiol 92: 305-306.

2. McConnell MV, Ganz P, Selwyn AP, Li W, Edelman RR, et al. (1995) Identification of anomalous coronary arteries and their anatomic course by magnetic resonance coronary angiography. Circulation 92: 3158-3162.

3. Angelini P, Velasco JA, Flamm S (2002) Coronary anomalies: Incidence, pathophysiology, and clinical relevance. Circulation 105: 2449-2454.

4. Namgung J, Kim JA (2014) The prevalence of coronary anomalies in a single center of Korea: Origination, course, and termination anomalies of aberrant coronary arteries detected by ECG-gated cardiac MDCT. BMC Cardiovasc Disord 14: 48.

5. Murphy E (2000) Cardiology review. ( $2^{\text {nd }}$ edn), WB Saunders Company, Philadelpha, 871-875.

6. Capodanno D, Alfonso $F$, Levine $G N$, Valgimigli $M$, Angiolillo DJ (2018) ACC/AHA versus ESC guidelines on dual antiplatelet therapy: JACC guideline comparison. J Am Coll Cardiol 72: 2915-2931.

7. Baber U, Dangas G, Chandrasekhar J, Sartori S, Gabriel Steg P, et al. (2016) Time-dependent associations between actionable bleeding, coronary thrombotic events, and mortality following percutaneous coronary intervention: Results from the PARIS Registry. JACC Cardiovasc Interv 9: 1349-1357.

8. Wallentin L, Becker RC, Budaj A, Cannon CP, Emanuelsson $\mathrm{H}$, et al. (2009) Ticagrelor versus Clopidogrel in patients with acute coronary syndromes. N Engl J Med 361: 10451057.

9. McQuaid KR, Laine L (2006) Systematic review and meta-analysis of adverse events of low-dose aspirin and Clopidogrel in randomized controlled trials. Am J Med 119: 624-638.

10. Mehran R, Baber U, Sharma SK, Cohen DJ, Angiolillo DJ, et al. (2019) Ticagrelor with or without Aspirin in high-risk patients after PCI. N Engl J Med 381: 2032-2042.

11. Kim BK, Hong SJ, Cho YH, Yun KH, Kim YH, et al. (2020) Effect of ticagrelor monotherapy vs ticagrelor with aspirin on major bleeding and cardiovascular events in patients with acute coronary syndrome. The TICO Randomized Clinical Trial. JAMA 323: 2407-2416. 